\title{
The sensitivity of Secondary Organic Aerosol component partitioning to the predictions of component properties - Part 2: Determination of particle hygroscopicity and its dependence on "apparent" volatility
}

\author{
D. O. Topping ${ }^{1,2}$, M. H. Barley ${ }^{1}$, and G. McFiggans ${ }^{1}$ \\ ${ }^{1}$ Centre for Atmospheric Sciences, School of Earth, Atmospheric \& Environmental Sciences, University of Manchester, \\ Manchester, M13 9PL, UK \\ ${ }^{2}$ National Centre for Atmospheric Science (NCAS), University of Manchester, Manchester, M13 9PL, UK
}

Received: 27 January 2011 - Published in Atmos. Chem. Phys. Discuss.: 16 March 2011

Revised: 5 July 2011 - Accepted: 11 July 2011 - Published: 3 August 2011

\begin{abstract}
A large number of calculations of absorptive partitioning of organic compounds have been conducted, making use of several methods to estimate pure component vapour pressures and activity coefficients $\left(p^{0}\right.$ and $\left.\gamma_{i}\right)$. The sensitivities of the predicted particle properties (density, hygroscopicity, CCN activation potential) to the choice of $p^{0}$ and $\gamma_{i}$ models and to the number of components used to represent the organic mixture have been systematically compared.

The variability in theoretical hygroscopic growth factor attributable to the choice of estimation technique increases with decreasing mixture complexity. Generally there is low sensitivity to the choice of vapour pressure predictive technique. The inclusion of non-ideality is responsible for a larger difference in predicted growth factor, though still relatively minor.

Assuming instantaneous equilibration of all semi-volatile on drying the aerosol to $0 \% \mathrm{RH}$ massively increases the sensitivity. Without such re-equilibration, the calculated growth factors are comparable to the low hygroscopicity of organic material widely measured in the laboratory and atmosphere. Allowing re-equilibration on drying produces a calculated hygroscopicity greater than measured for ambient organic material, and frequently close to those of common inorganic salts. Such a result has substantial implications on aerosol behaviour in instruments designed to measure hygroscopicity and on the degree of equilibration of semi-volatile components in the ambient atmosphere.
\end{abstract}

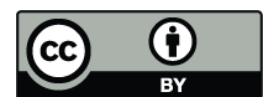

Correspondence to: G. McFiggans (g.mcfiggans@manchester.ac.uk)
The impacts of this variability on behaviour of particles as cloud condensation nuclei, on predicted cloud droplet number and uncertainty in radiative forcing are explored. When it is assumed only water evaporates on drying, the sensitivity in radiative forcing, " $\Delta F$ " to choice of $p^{0}$ and $\gamma_{i}$ estimation technique is low when the particle organic volume fraction is less than $55 \%$. Sensitivities increase with decreasing component complexity. If all components re-equilibrate on drying, the sensitivity of $\Delta F$ increases substantially for organic volume fractions as low as between 16 and $22 \%$ depending on the complexity of the organic composition and assumed aerosol size distribution. The current study ignores the impact of predicted changes in particle size which will increase uncertainty in droplet number and forcing.

\section{Introduction}

Aerosol particles remain highly uncertain contributors to climate change (Solomon et al., 2007). Both inorganic and organic material can transfer between the gas and particle phase. The composition of secondary organic aerosol (SOA) in the atmosphere is complex (Goldstein et al., 2007; Lewis et al., 2000; Hallquist et al., 2009; Bloss et al., 2005a,b; Aumont et al., 2005) and, as a result of its large contribution to the total aerosol mass, SOA will significantly contribute to the aerosol direct and indirect effects on climate (Haywood and Boucher, 2000; Forster et al., 2007). Aerosol schemes in large-scale models necessarily ignore the compositional complexity of the organic mixture and will continue to do so in the future. Empirical models of SOA formation by

Published by Copernicus Publications on behalf of the European Geosciences Union. 
definition ignore detailed chemistry or process information, lacking an ability to account for the complexity and dynamics of the SOA system. More complex explicit and semiexplicit models suffer from substantial uncertainties associated with fundamental model parameters (Hallquist et al., 2009). It is the impact of some of these uncertainties which form the focus of the present study. A primary driver for the transfer of organic material between the gas and condensed particulate phase is the vapour pressure of each of the partitioning components above the particulate composition. This is dependent on the vapour pressure of each compound in its pure state $\left(p_{i}^{0}\right)$ (vapour pressure of component $i$ above pure liquid (or sub-cooled liquid) $i$ ), multiplied by the component activity $\left(\gamma_{i}\right)$ or "effective" concentration in the complex mixture of components (ref) using an appropriate reference state. The partitioning constant $K_{p, i}$, in units of $\mathrm{m}^{3} \mu \mathrm{mol}^{-1}$ is given by Eq. (1):

$K_{p, i}=\frac{C_{i}^{\text {cond }}}{C_{i}^{\text {vap }} C_{\mathrm{OA}}}=\frac{R T f}{10^{6} \gamma_{i} p_{i}^{0}}$

where $C_{i}^{\mathrm{vap}}$ is the vapour phase molar concentration of component $\left(i, \mu \mathrm{mol} \mathrm{m}{ }^{-3}\right), C_{i}^{\text {cond }}$ is the condensed phase molar concentration of component $\left(i, \mu \mathrm{mol} \mathrm{m}^{-3}\right), C_{\mathrm{OA}}$ is the total molar concentration of condensed organic material $\left(\mu \mathrm{mol} \mathrm{m}{ }^{-3}\right), p_{i}^{0}$ is the saturated vapour pressure of component $(i, \mathrm{~atm}), R$ is the ideal gas constant $(8.2057 \times$ $10^{-5} \mathrm{~m}^{3}$ atm mol $\left.{ }^{-1} \mathrm{~K}^{-1}\right), T$ is the temperature (K), $f$ is the fraction of the condensed material that may be considered absorptive (usually considered unity for most absorptive partitioning calculations) and $\gamma_{i}$ is the activity coefficient for component $i$ in the liquid phase (dimensionless).

McFiggans et al. (2010) presented a large number of calculations of the absorptive partitioning of organic compounds using several methods to predict the component vapour pressures, $\left(p_{i}^{0}\right)$, and activity coefficients, $\left(\gamma_{i}\right)$. As the number of organic compounds used within atmospheric studies can vary dramatically, partitioning calculations were carried out using 2, 10, 100, 1000 and 10000 compounds for a range of ambient conditions $(\mathrm{RH}=60,80,90 \%, T=273.15,298.15$, $313.15 \mathrm{~K})$ to assess the impact of complexity. The sensitivities of the predictions in terms of the condensed component masses, volatility, $\mathrm{O}: \mathrm{C}$ ratio, molar mass and functionality distributions to the choice of $p_{0}$ and $\gamma_{i}$ models and to the number of components to represent the organic mixture was systematically compared. The authors found that the condensed component mass was highly sensitive to the vapour pressure model, and less sensitive to the inclusion of mixture non-ideality. The sensitivity to the change in property estimation method increased substantially with increased simplification of the organic mixture. This was a general finding and was clearly evident in terms of the predicted component functionality, O:C ratio, molar mass and volatility distributions of the condensed organic components. In this study, the results presented by McFiggans et al. (2010) are extended to assess the sensitivity of predicted hygroscopicity and $\mathrm{CCN}$ activation potential to uncertainty in $\left(p_{i}^{0}\right)$ and $\left(\gamma_{i}\right)$. The need for improved understanding of organics hygroscopicity and its representation in global models has already been highlighted in the literature (Liu and Wang, 2010). Considering this requirement, a parameterisation linking hygroscopicity to cloud droplet number, and thereby uncertainty in the radiative forcing by the aerosol first indirect effect, is used to estimate potential large scale impacts of the study, focusing on secondary organic aerosol only (SOA). This provides an assessment of the ability of reduction methodologies using current mechanistic techniques to reduce the complexity of organic aerosol and retain the capability to predict their properties.

\section{Methodology}

As detailed in the Appendix A2 and McFiggans et al. (2010), the combination of predictive techniques used for $\left(p^{0}\right)$ and $\left(\gamma_{i}\right)$ are listed in Table 1 for reference. Propagation of the sensitivities to hygroscopicity and $\mathrm{CCN}$ activation potential requires calculation of pure and multi-component density (see Appendix A1) and then aerosol size at different relative humidities. The hygroscopicity can then be expressed as the growth factor, or ratio of wet to dry diameter at given relative humidity $(\mathrm{RH})$, frequently $90 \% \mathrm{RH}$. The hygroscopic diameter growth factor of an aerosol is calculated as follows:

$\mathrm{GF}_{D}=\sqrt[3]{\frac{m_{\mathrm{wet}} \rho_{\mathrm{dry}}}{m_{\mathrm{dry}} \rho_{\mathrm{wet}}}}$

where $m_{\text {wet }}$ and $\rho_{\text {wet }}$ the mass and density of the "wet" particle, $m_{\text {dry }}$ and $\rho_{\text {dry }}$ the mass and density of the "dry" particle. The calculation technique for pure and multicomponent densities used in this calculation is presented in the Appendix.

A single parameter $\kappa$ (Petters and Kreidenweis, 2007) is widely used to describe and link sub- and supersaturated measurements of hygroscopicity. The $\kappa$-value is derived directly from the difference in dry and wet size according to:

$S(D)=\frac{D^{3}-D_{\mathrm{d}}^{3}}{D^{3}-D_{\mathrm{d}}^{3}(1-\kappa)} \exp \left(\frac{4 \sigma_{s / a} M_{\mathrm{w}}}{R T \rho_{\mathrm{w}} D}\right)$

where $D_{\mathrm{d}}$ is the dry diameter $(m), D$ is the wet diameter ( $m$ $\left.-\mathrm{GF}_{D} \times D_{\mathrm{d}}\right), \kappa$ is the single parameter hygroscopicity value (dimensionless), $\sigma_{\mathrm{s} / \mathrm{a}}$ is the surface tension of the solution $(N / m), M_{\mathrm{w}}$ is the molar mass of water $\left(18 \mathrm{~g} \mathrm{~mol}^{-1}\right)$, and $\rho_{\mathrm{w}}$ is the density of water $\left(1000 \mathrm{~kg} \mathrm{~m}^{-3}\right)$.

It should be emphasised at this point that the inability to predict the surface tension of multicomponent organic mixtures from first principles (see Topping et al. (2007)) prevents explicit calculation of the Kelvin term at the high organic concentrations present at sub-saturation. This means that the hygroscopic growth factor results, and subsequent calculation of single hygroscopicity parameter (see Sect. 4 below) 
Table 1. Combinations of $\left(p^{0}\right)$ and $\left(\gamma_{i}\right)$ predictive techniques used within absorptive partitioning calculations.

\begin{tabular}{lllll}
\hline$\left(p^{0}\right)$ "VP" method & $\left(p^{0}\right)$ "Tb" method & $\left(\gamma_{i}\right)$ method & reference & notes \\
\hline Nanoolal & Nanoolal & ideal $\left(\gamma_{i}=1\right)$ & N/VP-N & "base case" \\
Nanoolal & Stein and Brown & ideal $\left(\gamma_{i}=1\right)$ & N-SB & \\
Nanoolal & Joback & ideal $\left(\gamma_{i}=1\right)$ & N-JR & \\
Myrdal and Yalkowsky & Nanoolal & ideal $\left(\gamma_{i}=1\right)$ & MY-N & \\
Myrdal and Yalkowsky & Stein and Brown & ideal $\left(\gamma_{i}=1\right)$ & MY-SB & \\
Myrdal and Yalkowsky & Joback & ideal $\left(\gamma_{i}=1\right)$ & MY-JR & \\
Nanoolal & Nanoolal & non-ideal $\left(\gamma_{i} \neq 1\right)$ & N/VP-N act & \\
\hline
\end{tabular}

are valid above around $100 \mathrm{~nm}$ diameter under sub-saturated conditions. Furthermore, it has been shown recently that bulk to surface partitioning of some surface active components (Sorjamaa et al., 2007; Topping, 2010; Raatikainen et al., 2011) will largely offset any reduction in critical supersaturation resulting from lowered surface tension, previously thought to be important above saturation. This justification is used here to allow approximate estimation of the critical supersaturation from predicted $\kappa$ using Eq. (3).

The dry diameter is that at $0 \% \mathrm{RH}$ and is frequently assumed to be that achieved in the pre-drying before measurements of hygroscopicity in instruments such as the hygroscopic tandem mobility analyser (HTDMA) (Swietlicki et al., 2008). In deriving those hygroscopicity parameters normally determined empirically, the behaviour of the aerosol within the HTDMA is replicated using two different assumptions. These assumptions, relating to the degree of equilibration of organic material attained on drying, are discussed in Sect. 3.1. The impacts of kinetically limited mass transfer or condensed phase reactions are not considered in this study.

To clarify, the following procedure is used:

1. Absorptive partitioning calculations are performed at $90 \% \mathrm{RH}$ using pre-defined mixing ratio of 2 compounds in the gas phase to represent a randomlygenerated organic functionality (see McFiggans et al. (2010)) for a detailed description of the initialisation procedure). The "base case" vapour pressure method is first used to estimate component volatility and the total mixing ratio is iteratively varied (maintaining the component relative abundance) to yield a total $10 \mu \mathrm{g} \mathrm{m}^{-3}$ of condensed material, with a core of $2 \mu \mathrm{g} \mathrm{m}^{-3}$. The calculation is repeated using each vapour pressure method and assumption of non-ideality, giving different condensed masses of each component.

2. The density of the condensed material at $90 \% \mathrm{RH}$, including water, is calculated using a simple mass fraction multicomponent density mixing rule (Tang and Munkelwitz, 1994). The pure component density of each compound is calculated using the structure based method of Girolami et al. (1994), the core prescribed a density of $1400 \mathrm{~kg} \mathrm{~m}^{-3}$ based on recommendations in the litera- ture (Hallquist et al., 2009; Ng et al., 2007; Healy et al., 2008).

3. The mass of material at $0 \% \mathrm{RH}$ is calculated using two assumptions: (a) only water evaporates on drying, leaving the condensed organic material at $90 \% \mathrm{RH}$ representing the dry material and (b) all semi-volatile compounds re-equilibrate on drying, requiring absorptive partitioning calculations at $0 \% \mathrm{RH}$ using the same total abundance used in partitioning calculations at $90 \% \mathrm{RH}$ (see Fig. 2).

4. The density of condensed material at $0 \% \mathrm{RH}$ is calculated using the multicomponent density mixing rule described in Appendix A1.

5. Hygroscopic diameter growth factors $\left(\mathrm{GF}_{D}\right)$ are calculated using the wet and dry density from 2 and 4 respectively and wet mass from 1 and dry mass from $3 a$ and $3 \mathrm{~b}$.

6. The single parameter hygroscopicity parameter, $\kappa_{\text {org }}$, values (Petters and Kreidenweis, 2007) are directly calculated from $\mathrm{GF}_{D}$, allowing a prediction of $\mathrm{CCN}$ activation behaviour (described in Sect. 5).

7. The calculation steps 1 to 6 are repeated for a 10000 compound representation of the randomly generated functionality (see Sect. 2.3 of McFiggans et al., 2010) to provide comparison of the predicted particle properties with increased mixture complexity.

8. The calculation steps 1 to 7 are repeated for the 1000 randomly-generated initialisations described in McFiggans et al. (2010).

9. $\kappa_{\text {org }}$-values are compiled across all predictive methods at each level of representation complexity and used in a parameterised function to calculate the potential variability in radiative forcing resulting from choice of the estimation techniques.

Note that the impact of the variation in the predicted condensed mass on the size of particles has not been evaluated. Absorptive partitioning is a bulk equilibrium prediction and 
carries no information about the size of particles. A modified approach to account for the impacts of the Kelvin term is required for this and is the subject of an ongoing study.

\section{Results}

The variability in the calculated hygroscopic growth factors of the predicted condensed mixtures are first presented at each level of organic complexity, along with sensitivity to the choice of pure component vapour pressures $\left(p^{0}\right)$ estimation technique and non-ideality $\left(\gamma_{i}\right)$ treatment. This variability is then propagated through to predictions of $\mathrm{CCN}$ activation through calculation of the $\kappa$-value of the mixture. The sensitivity is finally propagated through to radiative forcing variability using a recently published parameterisation (Wang et al., 2008). The variation in predicted multicomponent densities is presented in the Appendix.

\subsection{Aerosol hygroscopicity}

As stated in Sect. 2, the mass of material at $0 \% \mathrm{RH}$ has been alternatively calculated using two assumptions: (a) only water evaporates on drying, such that the condensed organic material at $90 \% \mathrm{RH}$ is identical to that present under dry conditions, (b) all semi-volatile compounds re-equilibrate on drying, requiring absorptive partitioning calculations at $0 \% \mathrm{RH}$ using the same total semi-volatile organic component mixing ratios used in partitioning calculations at $90 \% \mathrm{RH}$. Figure 1 displays schematics of both cases "a" and "b".

A comparison of the sensitivity of predicted hygroscopicity is shown in Fig. 2 under the assumption of no reequilibration of semi-volatile organic components on drying ("a"). The hygroscopic diameter growth factors and derived $\kappa$-value sensitivity to property estimation technique and complexity assumption are shown on the left and right axes respectively and the results are summarised in Table 2.

Under this assumption of water being the only semivolatile component to re-equilibrate between the wet and dry state, the impact of vapour pressure predictive technique for the 10000 compound simulations results in a narrow range of median growth factors between 1.21 to 1.24 . Within this very narrow range, the use of the JR boiling point method with its systematic overprediction of boiling point leads to slightly greater variability, the use of the MY vapour pressure technique reducing variability. For the 2 component test cases, the same pattern is observed, with larger variability introduced by using the JR method. Predicted growth factors for this level of complexity fall within a larger range, as reflected in the inter-quartile-range in Table 1 . The largest difference in median values caused by choice of $p^{0}$ techniques is only $\sim 0.03$. Using non-ideality within the calculations decreases the predicted growth factors for both the 2 and 10000 component testcase, as reflected in lower median values and increased inter-quartile range. These values fall within those a)
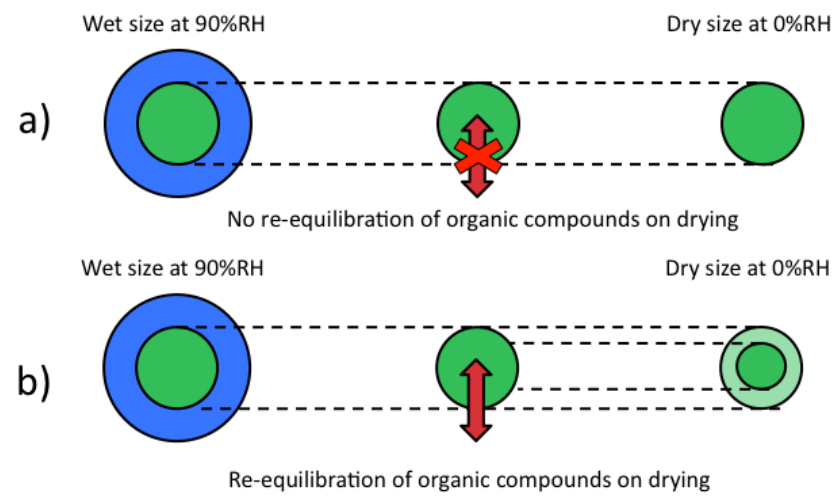

Fig. 1. Cartoon schematic illustrating the two different assumptions used in calculating the multicomponent particle hygroscopicity: (a) only water evaporates on drying, leaving the condensed organic material at $90 \% \mathrm{RH}$ representing the dry material. (b) All semi-volatile compounds re-equilibrate on drying, requiring absorptive partitioning calculations at $0 \% \mathrm{RH}$ using the same total abundance used in partitioning calculations at $90 \% \mathrm{RH}$. At the left side of the figure, each circle represents an aqueous aerosol (blue area equivalent to water and green equivalent to condensed organic material plus a core. The middle portion of the figure illustrates whether organic semi-volatiles are allowed to evaporate (single red arrow) or are not allowed to evaporate (crossed red arrow) on drying. The right portion of the figure illustrates the resulting aerosol at $0 \% \mathrm{RH}$, the light green representing the equivalent volume fraction that partitions into the gas phase on drying.

measured for organic aerosol created within chamber experiments and the atmosphere (Swietlicki et al., 2008; Wex et al., 2010). To summarise, the variability in theoretical growth factor caused by choice of predictive technique tends to increase with a decrease in compound complexity, with values all falling within a range consistent with measured values.

As summarised in Table 2, the trend in $\kappa$-values obviously reflects those in predicted $\mathrm{GF}_{D}$. Variation of the $p^{0}$ predictive technique leads to small difference in $\kappa$ with the use of the JR method causing largest variability and greatest difference of 0.015 between its median value and that of the base case in the 10000 compound simulations. The range of $\kappa$-values associated with the N-JR method is between 0.045 and 0.15 , the base case method 0.049 to 0.127 . Use of the MY technique reduces variability. Inclusion of non-ideality increases variability more than variation of $p^{0}$ technique, as referenced to the base case, with kappa values noteably decreasing. The difference in $\kappa$-values between the base case simulations for the 10000 compound case and the base case vapour pressure with non-ideality is 0.041 . For the 2 component testcase, the median is higher at 0.071 , with values ranging between 0.006 and 0.111 . Petters and Kreidenweis (2007) report that moderately hygroscopic organic species have CCN activities corresponding to $0.001<\kappa<0.5$, a range much larger than values displayed in Fig. 2. Very low $\kappa$ values (between 0.03 and 0.067 ) correspond to fulvic 
Table 2. Predicted hygroscopicity across all simulations. The first four rows present the hygroscopic diameter growth factor, GF ${ }_{D}$ variability with predictive technique, complexity and assumptions of equilibration on particle drying. The bottom four rows present the corresponding single parameter hygroscopicity $\kappa$-values. * Denotes an assumption of re-equilibration of all semi-volatiles on drying within the HTDMA (option "b") in Fig. 1. 10000 compound testcases outside brackets, 2 compound testcases in brackets.

\begin{tabular}{|c|c|c|c|c|c|c|c|c|c|}
\hline & N-N/VP act & N-N/VP & N SB & N-JR & MY-N & MY-SB & MY-JR & N-N/VP* & N-JR* \\
\hline Median & $1.12(1.18)$ & $1.21(1.2)$ & $1.22(1.2)$ & $1.24(1.21)$ & $1.2(1.2)$ & $1.2(1.2)$ & $1.23(1.21)$ & $1.57(1.76)$ & $1.44(1.26)$ \\
\hline Maximum & $1.26(1.34)$ & $1.28(1.29)$ & $1.28(1.27)$ & $1.31(1.33)$ & $1.23(1.26)$ & $1.23(1.25)$ & $1.31(1.3)$ & $1.94(2.39)$ & $1.71(2.3)$ \\
\hline Minimum & $1.02(1.01)$ & $1.17(1.13)$ & $1.17(1.14)$ & $1.19(1.12)$ & $1.17(1.18)$ & $1.17(1.15)$ & $1.19(1.12)$ & $1.35(1.12)$ & $1.29(1.11)$ \\
\hline IQR & $0.08(0.11)$ & $0.04(0.05)$ & $0.04(0.05)$ & $0.05(0.05)$ & $0.02(0.04)$ & $0.02(0.04)$ & $0.03(0.06)$ & $0.19(0.76)$ & $0.16(0.48)$ \\
\hline Median & $0.045(0.071)$ & $0.086(0.081)$ & $0.091(0.081)$ & $0.101(0.086)$ & $0.081(0.081)$ & $0.081(0.081)$ & $0.096(0.086)$ & $0.319(0.495)$ & $0.221(0.111)$ \\
\hline Maximum & $0.111(0.156)$ & $0.122(0.127)$ & $0.122(0.117)$ & $0.139(0.150)$ & $0.096(0.111)$ & $0.096(0.106)$ & $0.1387(0.15)$ & $0.700(1.406)$ & $0.444(1.241)$ \\
\hline Minimum & $0.006(0.003)$ & $0.067(0.049)$ & $0.067(0.054)$ & $0.076(0.045)$ & $0.067(0.071)$ & $0.067(0.058)$ & $0.076(0.045)$ & $0.162(0.045)$ & $0.127(0.041)$ \\
\hline IQR & $0.033(0.048)$ & $0.019(0.025)$ & $0.019(0.025)$ & $0.025(0.024)$ & $0.010(0.020)$ & $0.015(0.020)$ & $0.015(0.030)$ & $0.161(0.71)$ & $0.115(0.348)$ \\
\hline
\end{tabular}

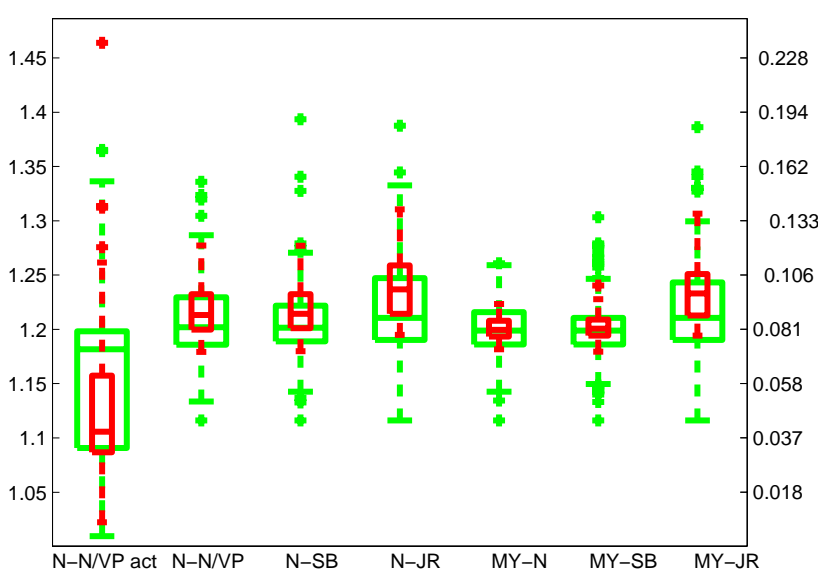

Fig. 2. Predicted growth factors as a function of predictive technique and number of compounds used in the partitioning calculations, assuming the only difference between the wet and dry sizes is that of the equilibrium water content. 10000 compound simulations are shown as red boxes, 2 compound simulations as green. Predictive technique acronyms displayed on the $\mathrm{x}$-axis are listed in Table 1. The left-hand y-axis lists calculated $\mathrm{GF}_{D}$, the right side lists the corresponding $\kappa$-values.

acid type substances. They report that a higher $\kappa$ value of 0.13 corresponds to a 1:2:2 levoglucosan:succinic:fulvic acid mixture. These range of $\kappa$-values bracket those values shown in Fig. 2. Even higher $\kappa$-values of around 0.2 upwards represent the most hygroscopic organic compounds such as levoglucosan, with inorganic salts exhibiting $\kappa$ values above 0.6 , much higher than the range of values displayed in Figs. 2 or 3, below. Aerosols generated in chamber experiments exhibit small $\kappa$ values. Wex et al. (2010) report $\kappa=0.1 \pm 0.04$ of aerosols derived from dark ozonolysis of alpha pinene. More generally, biogenic SOA are noted to have $\kappa$-values between 0.06-0.23, anthropogenic SOA between 0.06-0.14 and biomass burning organic aerosol between 0.06 and 0.3 (Prenni et al., 2007; King et al., 2007; Duplissy et al., 2008; Engelhart et al., 2008; Gunthe et al., 2009; King et al., 2009, 2010; Asa-Awuku et al., 2008; Carrico et al., 2008).
The most dramatic effect is observed if it is assumed that all semi-volatile compounds re-equilibrate on drying. In this case, the dry composition is recalculated by absorptive partitioning at $0 \% \mathrm{RH}$ using the same total abundance used in partitioning calculations at $90 \% \mathrm{RH}$. This is intuitively the case that might be expected using commonly employed ambient sampling techniques and yields most surprising results, with hygroscopic growth factors exceeding those measured under any reasonable atmospheric or even chamber conditions. Figure 3 shows the increase in the range of growth factors when equilibration of all semi-volatile components is considered in both the wet and dry states. The first three boxes and whiskers allowing only equilibration of water are shown for reference. The fourth and fifth sets of boxes and whiskers show results from simulations using the N-N/VP and N-JR methods, allowing all components to equilibrate denoted with the symbol *. In each case, red boxplots correspond to 10000 compound testcases, green 2 compound testcases. The sixth box and whiskers highlights the effect of assuming non-ideality in partitioning at $0 \% \mathrm{RH}$ using the base case vapour pressure method (N-N/VP). Comparison of the $\mathrm{N}-\mathrm{N} / \mathrm{VP}$ ideal simulations shows that the assumption of reequilibration on drying vastly increases the predicted growth factor (columns 2 and 4 in Fig. 3). The median value for the 10000 component testcase increases from 1.21 to 1.57 , and for the 2 component testcase from 1.22 to 1.76 . Furthermore, the sensitivity to complexity increases, with the 2 component testcases having an inter quartile range of 0.76 at $90 \% \mathrm{RH}$. This is readily explained by the fact that allowing evaporation of all semi-volatiles on drying in each case leads to a smaller size at $0 \% \mathrm{RH}$. For the 2 component case, a significant portion of the condensed SOA is comprised of only 2 compounds with varying volatility. For the 10000 compound case there is a much higher probability that the "full" range of volatilities are represented within the mixture, leading to a less dramatic change in size. This was illustrated by McFiggans et al. (2010) who showed the compounds used within the range of simulations exhibited an atmospherically representative range of volatility for the most complex testcases 


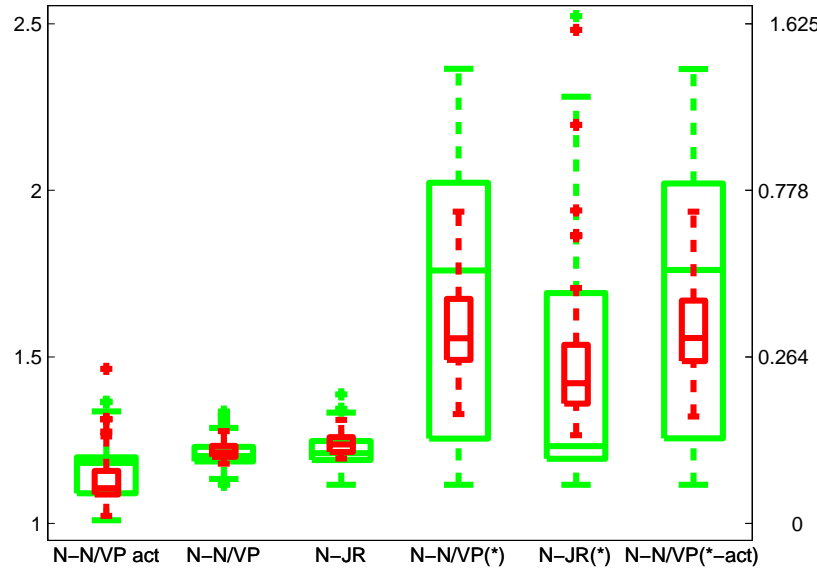

Fig. 3. Predicted growth factors as a function of predictive technique and number of compounds used in the partitioning calculations. The three bars on the left only allow water to equilibrate with the ambient humidity (and are the same as the first, second and fourth bars of Fig. 2), the three bars on the right with very much greater variability (denoted "*") use the same techniques but assume re-equilibration of all semi-volatiles on drying within the HTDMA (case "b" in Fig. 1). Note that (*-act) refers to the case where non-ideality was assumed to play a role on drying, i.e. for a nonaqueous aerosol at $0 \%$ RH. As in Fig. 2, 10000 compound simulations are shown as red boxes, 2 compound simulations as green and the predictive technique acronyms displayed on the $\mathrm{x}$-axis are listed in Table 1. The left-hand y-axis lists calculated $\mathrm{GF}_{D}$, the right side lists the corresponding $\kappa$-values.

using the base case vapour pressure combination. On the other hand, for the 2 component testcases, it is impossible to cover a broad range of volatility. Using the N-JR combination, assuming equilibration of all components on drying also increases predicted growth factor, but to a lesser extent. This is simply a consequence of the JR method consistently underpredicting volatility of individual components, with a consequent reduced mass lost on drying in this case, leading to a smaller difference in size. Again, the 10000 compound testcases exhibit smaller variability with a median of 1.44 and inter quartile range of 0.16 . In all cases, therefore, sensitivity to choice of predictive method increases when it is assumed that all semivolatile components equilibrate under both dry and wet conditions. If these predicted sensitivities are reasonable, it appears evident that semi-volatile organic components present in secondary aerosol in the atmosphere or smog chambers do not equilibrate in instruments designed to expose them to varying humidity. A discussion of the possibility of equilibration occuring within the instruments aiming to measure hygroscopicity, and potential reasons for disequilibria (such as kinetic limitation in the gaseous or condensed phases), is beyond the scope of this paper. However, discrepancies in measurements of SOA particle hygroscopicity with multiple instruments have been reported in chamber experiments that could be attributable to effects such as those described here (Good et al., 2010; Duplissy et al., 2009), as has failure to achieve closure under nitrate rich conditions attributed to HTDMA evaporation of semi-volatiles (Gysel et al., 2007). Within the HTDMA system, there are a number of potential artefacts. As a particle is deflected across the gas flow streamlines in a DMA, it potentially moves from higher concentrations of semi-volatile vapours in the sample air into lower concentrations in the sheath air, shrinking as it is being sized. This can occur in the first DMA where it is sized dry. In the second DMA where it is sized wet, the sample flow will already have been stripped of semi-volatile vapours, so shrinkage may occur throughout the trajectory through the instrument. In the drier before DMA 1, there is the potential for shrinkage as a result both of the intentional evaporation of water and the unintentional stripping of other semi-volatile vapours. In the humidification section, shrinkage by evaporation of semi-volatile components will be accompanied by hygroscopic growth. The net effect on growth factor will depend on the shrinkage prior to initial sizing and that prior to final sizing, in turn depending on the time spent in each section and whether the volatile material has time to evaporate in each section. Direct evidence that semi-volatile repartitoning can take place is provided by use of the TDMA to derive pure component vapour pressures from measurement of the shrinkage of particles of known composition (Bilde et al., 2003).

Tracking the growth factors, assuming re-equilibration on drying increases the predicted $\kappa$-value and sensitivity to choice of predictive technique used in the partitioning calculations. For the 2 component testcases and the base case vapour pressure method the range of $\kappa$-values now lie between 0.045 and 1.406 , the median increasing from 0.081 to 0.495 . For the 10000 compound testcases, the values lie between 0.162 to 0.57 , the median increasing from 0.086 to 0.319 . As before, the use of the JR boiling point method decreases the range of $\kappa$ values when assuming re-equilibration on drying, reflecting the underprediction of component volatility. Using the base case vapour pressure method, the range of predicted $\kappa$ values now cover a range that includes common inorganic salts $(>0.6$ Petters and Kreidenweis, 2007), far higher than observed in the laboratory or field.

The $\kappa$-value can be used to predict the critical supersaturation required to activate a particle of a given composition and size into a cloud droplet. Figure 4 reproduces the plot presented in Petters and Kreidenweis (2007) of the critical supersaturation as a function of particle dry size and $\kappa$-value. The solid lines represent the assumption of no evaporation of any organic compounds on drying, the dashed lines evaporation on drying. The upper and lower limits are taken from the difference between the N-N/VP-act and N-JR predictive techniques, an upper limit of $\kappa=0.9$ used for illustrative purposes. The red lines represent 10000 component testcases, the green the 2 component testcases. The resultant critical 


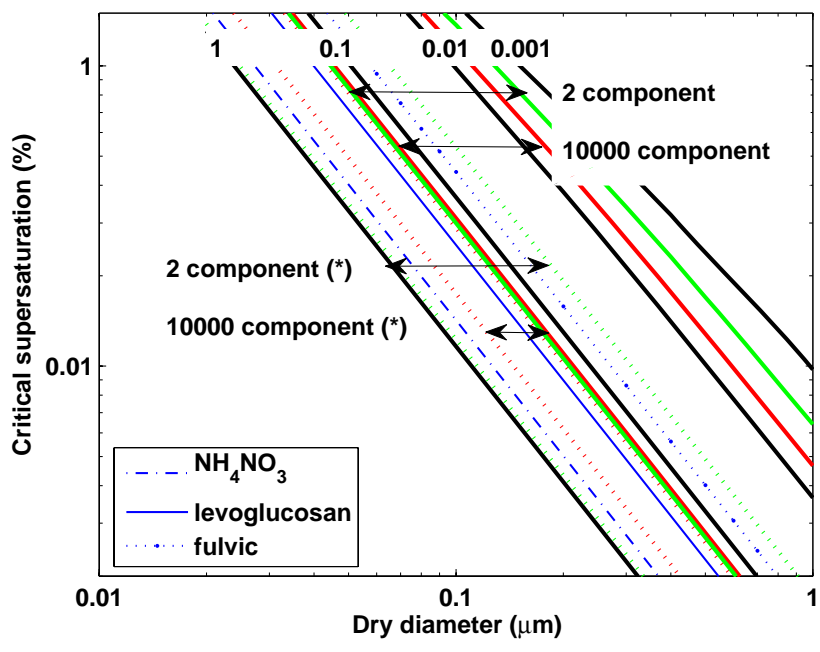

Fig. 4. Critical supersaturation (" $S_{\text {crit }}$ ", $\%$ ) versus dry diameter as a function of $\kappa$ value. Each solid black line highlights the relationship between $S_{\text {crit }}$ and diameter for 4 reference $\kappa$ values. The $\kappa$ values derived from simulations assuming no re-equilibration of all semi-volatiles on drying are highlighted as solid green and red lines (green: 2 compound simulations, red: 10000 compound simulations). The horizontal arrows span the range of $\kappa$ values. The $\kappa$ values derived from simulations assuming re-equilibration of all semi-volatiles on drying are displayed as dotted green and red lines. 3 example compounds are shown as blue lines, described in the legend.

supersaturations required for activation into a cloud droplet for a $100 \mathrm{~nm}$ aerosol are given in Table 3. For 2 compound simulations, $S_{\text {crit }}$ ranges from 0.3 to 1.37. Similarly, for 10000 compound simulations, the range is between 1.15 and 0.31 . Four different kappa values, equally spaced logarithmically, are displayed for reference as black solid lines. If it is assumed that organics evaporate on drying, the range of critical supersaturations, whilst higher, display smaller variability (between 0.54 and 0.12 for the 2 component and 0.29 and 0.17 for the 10000 component testcases). It is important to note that the properties of the organic mixtures change completely, as reflected by 3 reference lines representative of 2 different organic compounds and ammonium nitrate (assuming no equilibration between the gas and condensed phase for ammonium nitrate).

\subsection{Sensitivity in uncertainties of cloud droplet number and radiative forcing}

Liu and Wang (2010) recently studied the sensitivity of aerosol indirect forcing to the hygroscopicity of primary organic aerosol (POA) and SOA. The authors found that uncertainty in $\kappa$ values, based on current understanding, may lead to uncertainties comparable or even larger than those due to autoconversion parameterisation and tuning parameters related to entrainment, drizzle and snow formation. Im-
Table 3. Range of critical supersaturation (\%) for an $100 \mathrm{~nm}$ dry particle based on kappa values derived assuming: (no evap) no re-equilibration of organic semi-volatiles on drying and (evap) reequilibration of all organic semi-volatiles on drying. Upper and lower limits taken from difference between N-N/vp act and N-JR predictive techniques listed in table (3)

\begin{tabular}{llrr}
\hline \multirow{2}{*}{ Complexity } & $\begin{array}{l}\text { Drying } \\
\text { assumption }\end{array}$ & $\begin{array}{r}\text { Upper } \\
\text { Scrit }\end{array}$ & $\begin{array}{r}\text { Lower } \\
\text { Scrit }\end{array}$ \\
\hline 2 compounds & no evap & 1.37 & 0.3 \\
& evap & 0.54 & 0.12 \\
\hline \multirow{2}{*}{10000 compounds } & no evap & 1.15 & 0.31 \\
& evap & 0.29 & 0.17 \\
\hline
\end{tabular}

portantly, the authors in that study focused on both POA and SOA, whilst in this study focus is only given to the bulk properties of SOA. Using prescribed size distributions and particle hygroscopicity, the parameterisation presented by Wang et al. (2008) allows assessment of the impact of particle $\kappa$ value on stratocumulus cloud droplet number and radiative forcing by the first indirect effect, for specific environments as a function of organic volume fraction within the aerosol. Assuming internally mixed aerosol, the error in the first indirect effect can be calculated using:

$\Delta F=-0.7 \frac{n\left(\ln D_{p c}\right)}{N_{\mathrm{CCN}}} \ln \frac{0.7\left(1-x_{\mathrm{org}}\right)+\bar{\kappa}_{\mathrm{org}} x_{\mathrm{org}}}{0.7\left(1-x_{\mathrm{org}}\right)+\kappa_{\mathrm{org}} x_{\mathrm{org}}}$

where $\Delta F$ is the error in the aerosol first indirect effect $\left(\mathrm{W} \mathrm{m}^{-2}\right), \frac{n\left(\ln D_{p c}\right)}{N_{\mathrm{CCN}}}$ depends on the shape of the size distribution and supersaturation, $\kappa_{\text {org }}$ is the variable organic kappa value, $\bar{\kappa}_{\text {org }}$ is the prescribed average kappa value across all environments and $x_{\mathrm{org}}$ is the mole fraction of organic.

For free tropospheric and boundary layer aerosols, the average value of $\frac{n\left(\ln D_{p c}\right)}{N_{\mathrm{CCN}}}$ is 1.6 and 1.35 respectively (Wang et al., 2008), but ranges from 0.2 to 2.3 for marine, rural, urban and remote continental aerosol (?). Following Wang et al. (2008), we restrict our analysis to values of 1.3 and 0.9 for marine aerosols. $x_{\text {org }}$ is varied to assess the sensitivity of choice on property predictive technique on the derived $\kappa$ value.

Figure 5 plots the estimated uncertainties in the first indirect aerosol effect when using a constant $\bar{\kappa}_{\text {org }}$ of 0.12 for all organic species in an internal mixture. This value is chosen to represent the median value for ambient organics (Wang et al., 2008). The range of $\kappa_{\text {org }}$ values were taken from Table 2 assuming that the only semi-volatile component that changes on drying is water. It can be seen that the sensitivity of $\Delta F$ to derived kappa value increases as the molar volume of organic increases for both values of $\frac{n\left(\ln D_{p c}\right)}{N_{\mathrm{CCN}}}$. In all cases, sensitivities are largest for smaller values of $\frac{n\left(\ln D_{p c}\right)}{N_{\mathrm{CCN}}}$ for all volume fractions of organics. Wang et al. (2008) conclude that for typical aerosol size distributions and a range of 

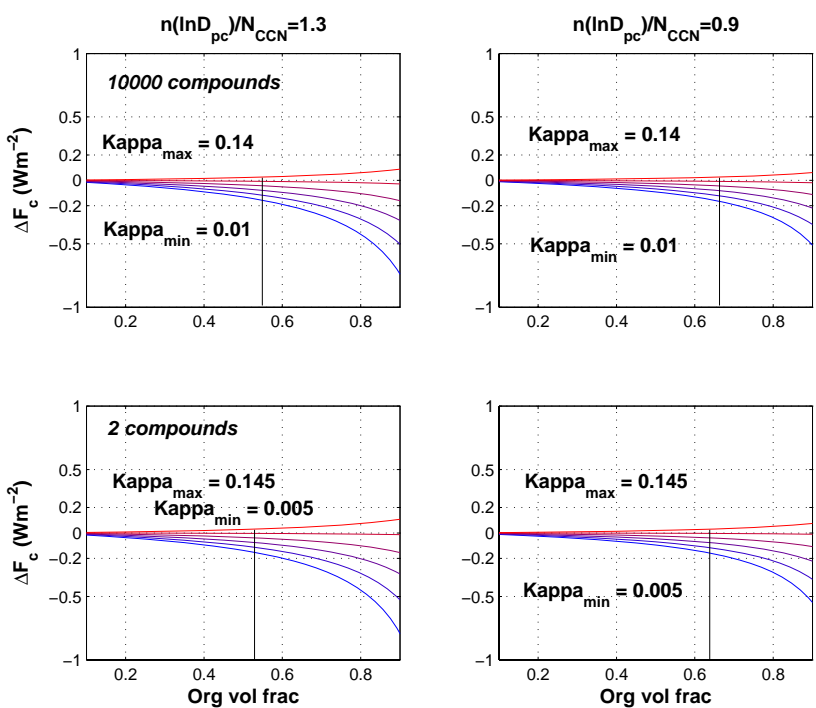

Fig. 5. Uncertainty in the first indirect effect $\Delta F$ as a function of $\kappa_{\text {org }}$ and $x_{\text {org }}$ (organic volume fraction). The range of $\kappa_{\text {org }}$ were derived from simulations assuming no re-equilibration of all semivolatile components to the dry state using two different methods to calculate $p^{0}$. The maximum $\kappa_{\text {org }}$ is represented by the top red line, the minimum $\kappa_{\text {org }}$ represented by the blue line. Each column represents two different size distributions, the top plots 10000 compound simulations, the bottom plots 2 compound simulations.

"expected" $\kappa_{\mathrm{org}}$, the predicted $\mathrm{CCN}$ and the corresponding first indirect aerosol effect are insensitive to the properties of organic species when the volume fraction of aerosol organics is less than $70 \%$. The cutoff value in $\Delta F$ was chosen to be $0.2 \mathrm{~W} \mathrm{~m}^{-2}$, corresponding to less than $10 \%$ uncertainty in predicted CCN. In other words, when organic volume fraction was lower than $\sim 60 \%$, using $\bar{\kappa}_{\text {org }}$ of 0.12 leads to $\Delta F$ of less than $0.2 \mathrm{~W} \mathrm{~m}^{-2}$. For the 10000 compound simulations and $\frac{n\left(\ln D_{p c}\right)}{N_{\mathrm{CCN}}}$ of 1.3 , at an organic volume fractions of $\sim 55 \%$, the range of $\kappa_{\text {org }}$-values derived using different predictive techniques causes a change in $\Delta F$ of $0.2 \mathrm{~W} \mathrm{~m}^{-2}$ from net cooling to slight net warming. As organic compounds increasingly dominate, the sensitivity increases substantially. At $90 \%$ organic volume fraction, $\Delta F$ changes from $\sim 0.1 \mathrm{~W} \mathrm{~m}^{-2}$ to $-0.75 \mathrm{~W} \mathrm{~m}^{-2}$, a dramatic change in sign and magnitude. Sensitivities are slightly larger for the 2 component simulations but not noticeably so. Changing $\frac{n\left(\ln D_{p c}\right)}{N_{\mathrm{CCN}}}$ to 0.9 reduces the uncertainties slightly, the organic volume fraction of organics at which $\Delta F$ changes by $0.2 \mathrm{~W} \mathrm{~m}^{-2}$ increasing from $55 \%$ to $66 \%$.

Figure 6 plots the same sensitivities for the range of kappa values derived assuming re-equilibration of all organic compounds on drying. The difference in sensitivity to $\Delta F$ is substantial. For $\frac{n\left(\ln D_{p c}\right)}{N_{\mathrm{CCN}}}$ of 1.3 , the organic molar volume at which $\Delta F$ changes by $0.2 \mathrm{~W} \mathrm{~m}^{-2}$ changes from $70 \%$ to $22 \%$ for the 10000 compound simulations. For 2 compound
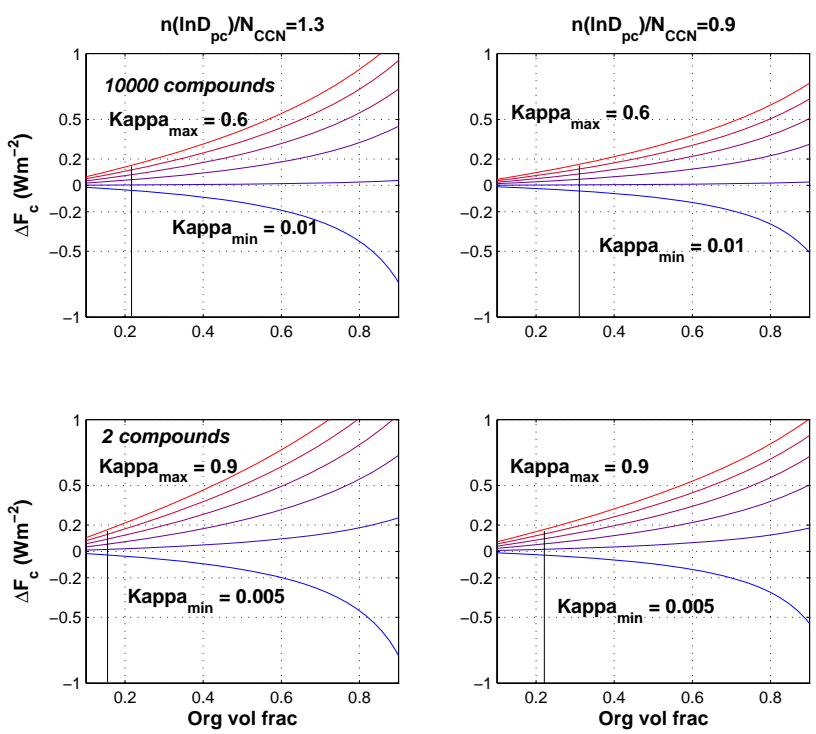

Fig. 6. Uncertainty in the first indirect effect $\Delta F$ as a function of $\kappa_{\text {org }}$ and $x_{\text {org }}$. The range of $\kappa_{\text {org }}$ were derived from simulations assuming re-equilibration of all semi-volatile components to the dry state using two different method to calculate $p^{0}$. The maximum $\kappa_{\text {org }}$ is represented by the top red line, the minimum $\kappa_{\text {org }}$ represented by the blue line. Each column represents two different size distributions, the top plots 10000 compound simulations, the bottom plots 2 compound simulations.

simulations this value drops to $16 \%$. For $\frac{n\left(\ln D_{p c}\right)}{N_{\mathrm{CCN}}}$ of 0.9 , these values increase slightly to $31 \%$ and $22 \%$ respectively. As the organic compounds begin to dominate, the uncertainty in $\Delta F$ increases significantly with differences in $\Delta F$ of $1 \mathrm{~W} \mathrm{~m}^{-2}$ at organic volume fractions greater than $60 \%$ for 2 component simulations. The reduction in sensitivity to increasing organic complexity is evident as the change in $\Delta F$ decreases to $0.72 \mathrm{~W} \mathrm{~m}^{-2}$ at the same volume fraction for 10000 compounds.

To summarise, when it is assumed that semi-volatile organic compounds do not equilibrate on drying, the propogated sensitivity of $\Delta F$ to variability in predicted $\kappa_{\mathrm{org}}$, dependent on choice of predictive technique in absorptive partitioning calculations, is insenstive for organic volume fractions less than $55 \%$, although, at these concentrations, $\Delta F$ changes sign from a negative to positive forcing. Any sensitivities which do exist, increase with decreasing component complexity. This apparent lack of sensitivity for "moderate" molar volumes of condensed organic material was already noted by Liu and Wang (2010) who found the choice of SOA $\kappa_{\text {org }}$ had a relatively small impact on calculated CCN concentration for present day simulations due to internal mixing with high-hygroscopic inorganic species. However, the authors also rightly point out that the change in $\kappa_{\text {org }}$ from preindustrial to present day simulations as a result of anthropogenic influence may lead to additional uncertainty. In this study, if it is assumed that semi-volatile organic compounds 
re-equilibrate on drying, the sensitivity of $\Delta F$ to choice of predictive technique and complexity increases subtantially. In this case the concentration of organics at which the sensitivity of $\Delta F$ to choice of predictive technique becomes insensitive drops to between 16 and $22 \%$ depending on the complexity of the organic composition and aerosol size distribution, represented by $\frac{n\left(\ln D_{p c}\right)}{N_{\mathrm{CCN}}}$. A value for $\kappa_{\mathrm{org}}$ of 0.9 is clearly very high and does not compare well with measured SOA growth factors. However, use of the substantially lower predicted values implies that water is the only semivolatile component equilibrating between the wet and dry states. This has important implications.

It should be noted that the choice of predictive technique has two distinct effects on $\Delta F$. For prescribed organic volume fractions, the sensitivity of $\Delta F$ to the change in $\kappa_{\text {org }}$ resulting from the choice of predictive technique has been investigated. The second impact on $\Delta F$ results from the change in the particle size distribution resulting from variation in the predicted mass on changing property estimation technique. It was shown by McFiggans et al. (2010) that this sensitivity was substantial. However, the absorptive partitioning calculations do not directly carry consideration of particle size and the sensitivity to this effect is the subject of ongoing work. Furthermore, the organic volume fraction will be directly influenced by the choice of estimation technique. Both effects may lead to considerable impacts on $\Delta F$.

\section{Conclusions and future work}

A large number of calculations of absorptive partitioning of organic compounds have been made using a number of methods to predict pure component vapour pressures and activity coefficients $\left(p^{0}\right.$ and $\left.\gamma_{i}\right)$. The sensitivities of the predictions in terms of the resulting particle density, hygroscopicity and $\mathrm{CCN}$ activation potential to the choice of $p^{0}$ and $\gamma_{i}$ models and to the number of components to represent the organic mixture have been systematically compared.

Hygroscopic growth factors and derived single parameter hygroscopicity $\left(\kappa_{\text {org }}\right)$-values have been calculated using two assumptions of equilibration under wet and dry conditions: (a) only water evaporates on drying, such that the condensed organic material at $90 \% \mathrm{RH}$ is the same as that present when dry and (b) all semi-volatile compounds attain equilibrium under dry and wet conditions. In general, the variability in theoretical growth factor caused by choice of predictive technique tends to increase slightly with a decrease in compound complexity. For choice of technique used to calculate $p^{0}$, inclusion of the Joback and Reid boiling point method marginally increases variability owing to the systematic under-prediction of component volatility. In contrast to the greater sensitivity of condensed component mass to the choice of vapour pressure estimation technique for in McFiggans et al. (2010), the predicted hygroscopicity was found to be more sensitive to inclusion of non-ideality.
An overwhelming sensitivity of all properties was found to the assumption of equilibration of components. Assuming that all semi-volatile components re-equilibrate with the gas phase on drying the aerosol to $0 \% \mathrm{RH}$ as might reasonably be expected, vastly increases the sensitivity of predicted growth factors to choice of estimation technique and to the number of components used in the partitioning calculations and produces higher calculated hygroscopicity values than commonly measured. Assuming no re-equilibration leads to calculated growth factors consistent with the low values for organic compounds derived from ambient and chamber measurements, much lower than those of common inorganic salts. Several possible explanations exist with implications for hygroscopicity measurements:

1. semi-volatile organic compounds are kinetically prevented from completely attaining equilibrium under dry and/or wet conditions (i.e. do not fully shrink and/or grow),

2. for unknown reasons, the gaseous mixing ratio of condensable organic compounds increases as water vapour mixing ratio decreases in all cases such that it would approximately offset the tendency of the organic component to evaporate on drying as a result of the increased mole fraction and hence vapour pressure. This would appear to require a substantial coincidence for which there is no ready explanation,

3. despite our best attempts to target the simulations, and contrary to the evidence provided by McFiggans et al. (2010), the organic components in the simulations are unrepresentative of those in atmospheric particulates in a manner that systematically leads to enhanced hygroscopicity. This would be an unfortunate and unforeseen result and is not readily supported,

4. organic components measured in the laboratory or the ambient atmosphere are never dominated by semivolatile components susceptible to reversible absorptive partitioning and the particle hygroscopicity is determined by components that do not equilibrate between the wet and dry states.

It is probable that some combination of 1 and 4 is responsible for the discrepancy between measured and predicted behaviour. This is of substantial consequence to ambient measurements of hygroscopicity and attempts to reconcile subsaturated and supersaturated water uptake.

It should be noted that full equilibration could conceivably lead to smaller or larger particles under dry conditions. If the majority of the mass of dry particle comprised components that were sufficiently hydrophobic that they would be present at greater abundance in the absence rather than presence of water, then the dry mass would be greater when assuming full equilibration when non-ideality was assumed, than just assuming water evaporates on drying. That this is 
never the case in 1000 randomised initialisations gives strong indication that more condensed SOA mass would always be formed in a moist rather than a dry environment by absorptive partitioning under the conditions of these simulations. Of course, this may be substantially less than if the components were ideally mixed. Furthermore, the condensing compounds could be more hydrophobic than those produced by the semi-random initialisations. However, McFiggans et al. (2010) showed that the predicted O:C ratios in the simulations were comparable to those observed in the ambient atmosphere, so no systematic bias in hygroscopicity should be obviously expected. It is difficult to prescribe evidence based probabilities to either of the above scenarios. However, if water were to play no role, or a inhibitory role, in absorptive partitioning, dry particles would be comparable or even larger in size than moist particles.

The impacts of uncertainty in hygroscopicity on single particle CCN activation potential and cloud droplet number/radiative forcing uncertainty have been explored using common parameterisations. When it is assumed that semivolatiles do not equilibrate on drying, the propagated sensitivity in radiative forcing " $\Delta F$ " to variability in predicted $\kappa_{\text {org }}$, dependent on choice of predictive technique in absorptive partitioning calculations, is insensitive for organic volume fractions less than $55 \%$. Although, at these concentrations, $\Delta F$ changes sign from a negative to positive forcing. Any sensitivities which do exist, increase with decreasing component complexity. If it is assumed that semi-volatiles re-equilibrate on drying, the sensitivity of $\Delta F$ to choice of predictive technique and complexity increases substantially. In this case the concentration of organics at which the sensitivity of $\Delta F$ to choice of predictive technique becomes insensitive drops to between 16 and $22 \%$ depending on the complexity of the organic composition and aerosol size distribution. The impact of predictive technique on condensed mass should be included in future sensitivity studies as this can only increase propagated uncertainties in $\Delta F$.

\section{Appendix A}

\section{A1 Calculation of pure component and multicomponent density for use in hygroscopicity calculation}

To calculate the pure component density of each compound the structure based method of Girolami et al. (1994) is used. The authors claim accuracy to within $100 \mathrm{~kg} \mathrm{~m}^{-3}$ for a wide variety of liquids, yielding estimates that are within 2 or $3 \%$ of the actual density. The scaled volume of the molecule is simply the sum of its constituent atoms and the density is then related to the total mass. Modifications are prescribed for molecules containing the hydroxyl, carboxyl, primary and secondary amino and amide groups. The range of pure component densities for simulations with 2 and 10000 com-

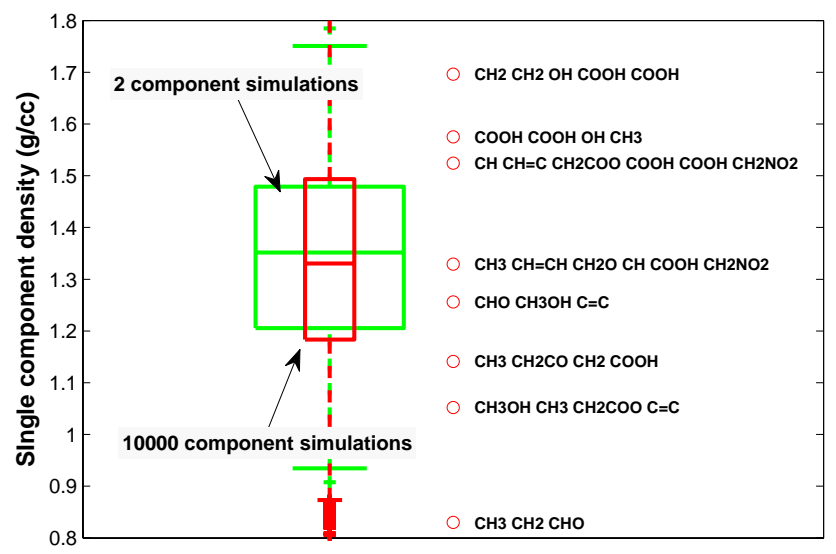

Fig. A1. Boxplots showing the range of individual compound densities used in the simulations described by McFiggans et al. (2010). The Green boxplot shows the range for 2 compound simulations, the red 10000 compound simulations. The open red circles show examples of the calculated densities of individual compounds constructed using UNIFAC subgroups within the simulations described by McFiggans et al. (2010).

pounds used within the partitioning calculations are shown in Fig. A1. The range of values are fairly equal, suggesting a uniform representation of organic composition across both levels of complexity. This is to be expected, since Fig. 1b) in McFiggans et al. (2010) demonstrated that the semi-random initialisations provided a uniform contribution from each functional groups at each complexity representation across the 1000 sets of simulations. Also shown in Fig. A1 for reference are calculated densities for several randomly selected compounds used within the simulations. Laboratory measurements of SOA formed from anthropogenic and biogenic precursors yield aerosol effective densities in the range 1060 to $1450 \mathrm{~kg} \mathrm{~m}^{-3}$ and 640 to $1650 \mathrm{~kg} \mathrm{~m}^{-3}$ respectively (Bahreini et al., 2005; Alfarra et al., 2006; Kostenidou et al., 2007; Hallquist et al., 2009). A density of $1400 \mathrm{~kg} \mathrm{~m}^{-3}$ has been determined for SOA generated from isoprene (Dommen et al., 2006; $\mathrm{Ng}$ et al., 2007) and aromatic (Alfarra et al., 2006; Ng et al., 2007) oxidation by comparing mobility diameter measurements from a differential mobility analyzer with the vacuum aerodynamic diameter measured with an on-line aerosol mass spectrometer. In the absence of direct measurements, it is recommended that a value of $1400 \mathrm{~kg} \mathrm{~m}^{-3}$ is used for the SOA density (Hallquist et al., 2009; Ng et al., 2007; Healy et al., 2008). We have therefore chosen $1400 \mathrm{~kg} \mathrm{~m}^{-3}$ for the core density.

Figure A1 indicates that the values used within this study are reasonable for atmospheric compounds. McFiggans et al. (2010) noted general patterns in the O:C ratio and molecular weight of aerosol resulting from the use of separate predictive methods. For example, the use of the JR boiling point method tends to consistently underpredict the volatility of individual compounds, leading to generally lower O:C ratios 
of the resulting aerosol. It is therefore reasonable to expect an impact of the variation in $\mathrm{O}: \mathrm{C}$ ratio on the density, thus growth factor. However, the correlation coefficient between the density of compounds and their O:C ratio for all of the 10000 compound simulations was found to be 0.0057 suggesting no relation between the two variables. The relationship is further complicated by the fact that McFiggans et al. (2010) also found that, despite general patterns in predictions of $\mathrm{O}: \mathrm{C}$ ratios and molecular weights of condensed material, there was substantial heterogeneity in condensed abundance of individual compounds as a function of $\mathrm{O}: \mathrm{C}$ ratios and molecular weights.

For multicomponent densities (both dry and wet), the ideal mixing rule is applied. Whilst it would be more accurate to not rely on this assumption, it is impossible to obtain empirical fits for all compounds studied here. This is given by Eq. (A1).

$$
\frac{1}{\rho_{\mathrm{total}}}=\sum_{i=1}^{N} \frac{x_{i}}{\rho_{i}}
$$

where $\rho_{\text {total }}$ is the density of the mixture, $x_{i}$ the mass fraction of component $i$ and $\rho_{i}$ the pure component density of component $i$. Results in Fig. A1 therefore provide upper and lower bounds on the predicted density of the total condensed material for a given core density.

\section{A2 Methodology used within absorptive partitioning calculations}

A number of methods are used to predict both $\left(p^{0}\right)$ and activities $\left(\gamma_{i}\right)$. This study uses the 2 and 10000 compound representations of the complexity of an organic mixed particles using the simulations described by McFiggans et al. (2010). The composition of each organic compound was based on 39 functional groups within the UNIFAC (Fredenslund et al., 1975) matrix as presented in Table 1 of McFiggans et al. (2010). Calculation of $p^{0}$ is split into two components: calculation of boiling point $\left(T_{\mathrm{b}}\right)$ and a method for extrapolation to ambient temperatures (VP). The different techniques for estimating both have been described in detail and assessed in Barley et al. (2010). In the present work $T_{\mathrm{b}}$ values were estimated by the methods of Nannoolal et al. (2004); Stein et al. (1994); Joback and Reid (1987) (henceforth be referred to as the N, SB and JR methods). The N method is the most complex group contribution method of the three and gave the best results when tested against experimental vapour pressure data for 45 multifunctional compounds (Barley et al., 2010). The SB method is much simpler, while the "JR" method consistently overestimates the $T_{\mathrm{b}}$ values of compounds with predicted $T_{\mathrm{b}}>500 \mathrm{~K}$. The VP methods used in this work were that of Nannoolal et al. (2008) and Myrdal and Yalkowsky (1997) (referred to as N/VP and MY methods). The N/VP method uses the same complex group contribution structure as the $T_{\mathrm{b}}$ estimation method. Barley et al. (2010) showed that the MY method significantly underestimated the slope of the vapour pressure line. The combination of predictive techniques used for $\left(p^{0}\right)$ and $\left(\gamma_{i}\right)$ are listed in Table 1 for reference.

In all of the partitioning simulations the abundance of compounds within the gas phase was adjusted to produce $10 \mu \mathrm{g} \mathrm{m}^{-3}$ of condensed material, with a core of $2 \mu \mathrm{g} \mathrm{m}^{-3}$, using the N-N/VP predictive technique combination. This is referred to as the 'base case' technique. The vapour pressure and treatment of non-ideality, were changed systematically and the impact on predicted mass and functionality of the condensed material was assessed. In total, 1000 sets of simulations were carried out to cover a broad range of functionality. The reader is referred to the initialisation procedure described in detail in Sect. 2.3 of McFiggans et al. (2010) for a full description of the preparation of the model scenarios.

Acknowledgements. This work was carried out within the UK NERC-funded "QUantifying the Earth SysTem" (QUEST) project under the "QUest Aerosol and Atmospheric Chemistry" (QUAAC) (grant number NE/C001613/1) and EU-funded "European Integrated project on Aerosol Cloud Climate and Air Quality interactions"(EUCAARI) under contract number 036833-2. DOT was supported by UK National Centre for Atmospheric Sciences (NCAS) funding. Additional support was provided by the NERCfunded "Vast Improvement" project NE/E018181/1.

Edited by: V.-M. Kerminen

\section{References}

Alfarra, M. R., Paulsen, D., Gysel, M., Garforth, A. A., Dommen, J., Prévôt, A. S. H., Worsnop, D. R., Baltensperger, U., and Coe, H.: A mass spectrometric study of secondary organic aerosols formed from the photooxidation of anthropogenic and biogenic precursors in a reaction chamber, Atmos. Chem. Phys., 6, 52795293, doi:10.5194/acp-6-5279-2006, 2006.

Asa-Awuku, A., Sullivan, A. P., Hennigan, C. J., Weber, R. J., and Nenes, A.: Investigation of molar volume and surfactant characteristics of water-soluble organic compounds in biomass burning aerosol, Atmos. Chem. Phys., 8, 799-812, doi:10.5194/acp-8799-2008, 2008.

Aumont, B., Szopa, S., and Madronich, S.: Modelling the evolution of organic carbon during its gas-phase tropospheric oxidation: development of an explicit model based on a self generating approach, Atmos. Chem. Phys., 5, 2497-2517, doi:10.5194/acp-52497-2005, 2005.

Bahreini, R., Keywood, M. D., Ng, N. L., Varutbangkul, V., Gao, S., Flagan, R. C., Seinfeld, J. H.,Worsnop, D. R., and Jimenez, J. L.: Measurements of secondary organic aerosol from oxidation of cycloalkenes, terpenes, and m-xylene using an Aerodyne aerosol mass spectrometer, Environ. Sci. Technol., 39, 5674-5688, 2005.

Barley, M. H. and McFiggans, G.: The critical assessment of vapour pressure estimation methods for use in modelling the formation of atmospheric organic aerosol, Atmos. Chem. Phys., 10, 749767, doi:10.5194/acp-10-749-2010, 2010.

Bloss, C., Wagner, V., Bonzanini, A., Jenkin, M. E., Wirtz, K., Martin-Reviejo, M., and Pilling, M. J.: Evaluation of detailed 
aromatic mechanisms (MCMv3 and MCMv3.1) against environmental chamber data, Atmos. Chem. Phys., 5, 623-639, doi:10.5194/acp-5-623-2005, 2005a.

Bloss, C., Wagner, V., Jenkin, M. E., Volkamer, R., Bloss, W. J., Lee, J. D., Heard, D. E., Wirtz, K., Martin-Reviejo, M., Rea, G., Wenger, J. C., and Pilling, M. J.: Development of a detailed chemical mechanism (MCMv3.1) for the atmospheric oxidation of aromatic hydrocarbons, Atmos. Chem. Phys., 5, 641-664, doi:10.5194/acp-5-641-2005, 2005b.

Carrico, C. M., Petters, M. D., Kreidenweis, S. M., Collett, J. L., Engling, G., and Malm, W. C.: Aerosol hygroscopicity and cloud droplet activation of extracts of filters from biomass burning experiments, J. Geophys. Res., 113, D08206, doi:10.1029/2007JD009274, 2008.

Dommen, J., Metzger, A., Duplissy, J., Kalberer, M., Alfarra, M. R., Gascho, A., Weingartner, E., Prevot, A. S. H., Verheggen, B., and Baltensperger, U.: Laboratory observation of oligomers in the aerosol from isoprene/NOx photooxidation, Geophys. Res. Lett., 31, L13805, doi:13810.11029/12006GL026523, 2006.

Duplissy J., Gysel,M., Alfarra,M.R., Dommen, J., Metzger, A., Prevot, A. S. H., Weingartner, E., Laaksonen, A., Raatikainen, T., Good, N.,Turner, S. F., McFiggans, G., and Baltensperger, U.: Cloud forming potential of secondary organic aerosol under near atmospheric conditions, Geophys. Res. Lett., 35, L03818, doi:10.1029/2007GL031075, 2008.

Duplissy, J., Gysel, M., Sjogren, S., Meyer, N., Good, N., Kammermann, L., Michaud, V., Weigel, R., Martins dos Santos, S., Gruening, C., Villani, P., Laj, P., Sellegri, K., Metzger, A., McFiggans, G. B., Wehrle, G., Richter, R., Dommen, J., Ristovski, Z., Baltensperger, U., and Weingartner, E.: Intercomparison study of six HTDMAs: results and recommendations, Atmos. Meas. Tech., 2, 363-378, doi:10.5194/amt-2-363-2009, 2009.

Engelhart, G. J., Asa-Awuku, A., Nenes, A., and Pandis, S. N.: $\mathrm{CCN}$ activity and droplet growth kinetics of fresh and aged monoterpene secondary organic aerosol, Atmos. Chem. Phys., 8, 3937-3949, doi:10.5194/acp-8-3937-2008, 2008.

Forster, P. V., Ramaswamy, P., Artaxo, T., Bernsten, T., Betts, R., and Fahey, D.: Changes in Atmospheric Constituents and in Radiative Forcing, in: Climate Change 2007: The Physical Science Basis, edited by: Solomon, S. D., Contribution of Working Group I to the Fourth Assessment Report of the Intergovernmental Panel on Climate Change, Cambridge, United Kingdom and New York, NY, USA, Cambridge University Press, 2007.

Fredenslund, A., Jones, R. L., and Prausnitz, J. M.: GroupContribution Estimation of Activity-Coefficients in Nonideal Liquid-Mixtures, Aiche J., 21, 1086-1099, 1975.

Girolami G. S.: A Simple "Back of the Envelope" Method for Estimating the Densities and Molecular Volume of Liquids and Volumes, J. Chemical Education, 71(11), 962-964, 1994.

Goldstein, A. H. and Galbally, I. E.: Known and unexplored organic constituents in the earths atmosphere, Environ. Sci. Technol., 41, 1514-1521, 2007.

Good, N., Topping, D. O., Duplissy, J., Gysel, M., Meyer, N. K., Metzger, A., Turner, S. F., Baltensperger, U., Ristovski, Z., Weingartner, E., Coe, H., and McFiggans, G.: Widening the gap between measurement and modelling of secondary organic aerosol properties?, Atmos. Chem. Phys., 10, 2577-2593, doi:10.5194/acp-10-2577-2010, 2010.

Gunthe, S. S., King, S. M., Rose, D., Chen, Q., Roldin, P., Farmer,
D. K., Jimenez, J. L., Artaxo, P., Andreae, M. O., Martin, S. T., and Pöschl, U.: Cloud condensation nuclei in pristine tropical rainforest air of Amazonia: size-resolved measurements and modeling of atmospheric aerosol composition and CCN activity, Atmos. Chem. Phys., 9, 7551-7575, doi:10.5194/acp-9-75512009, 2009.

Gysel, M., Crosier, J., Topping, D. O., Whitehead, J. D., Bower, K. N., Cubison, M. J., Williams, P. I., Flynn, M. J., McFiggans, G. B., and Coe, H.: Closure study between chemical composition and hygroscopic growth of aerosol particles during TORCH2, Atmos. Chem. Phys., 7, 6131-6144, doi:10.5194/acp-7-61312007, 2007.

Hallquist, M., Wenger, J. C., Baltensperger, U., Rudich, Y., Simpson, D., Claeys, M., Dommen, J., Donahue, N. M., George, C., Goldstein, A. H., Hamilton, J. F., Herrmann, H., Hoffmann, T., Iinuma, Y., Jang, M., Jenkin, M. E., Jimenez, J. L., Kiendler-Scharr, A., Maenhaut, W., McFiggans, G., Mentel, Th. F., Monod, A., Prévôt, A. S. H., Seinfeld, J. H., Surratt, J. D., Szmigielski, R., and Wildt, J.: The formation, properties and impact of secondary organic aerosol: current and emerging issues, Atmos. Chem. Phys., 9, 5155-5236, doi:10.5194/acp-95155-2009, 2009.

Haywood, J. and Boucher, O.: Estimates of the direct and indirect radiative forcing due to tropospheric aerosols: A review, Rev. Geophys., 38, 513-543, 2000.

Healy, R. M., Wenger, J. C., Metzger, A., Duplissy, J., Kalberer, M., and Dommen, J.: Gas/particle partitioning of carbonyls in the photooxidation of isoprene and 1,3,5-trimethylbenzene, Atmos. Chem. Phys., 8, 3215-3230, doi:10.5194/acp-8-3215-2008, 2008.

Juranyi, Z., Gysel, M., Duplissy, J., Weingartner, E., Tritscher, T., Dommen, J., Henning, S., Ziese, M., Kiselev, A., Stratmann, F., George, I., and Baltensperger, U.: Influence of gas-to-particle partitioning on the hygroscopic and droplet activation behaviour of alpha-pinene secondary organic aerosol, Phys. Chem. Chem. Phys., 11, 8091-8097, 2009.

Joback, K. G. and Reid, R. C.: Estimation of Pure-Component Properties from Group-Contributions, Chem. Eng. Commun., 57, 233-243, 1987.

King, S. M., Rosenoern, T., Shilling, J. E., Chen, Q., and Martin, S. T.: Cloud condensation nucleus activity of secondary organic aerosol particles mixed with sulfate, Geophys. Res. Lett., 34, L24806, doi:10.1029/2007GL030390, 2007.

King, S. M., Rosenoern, T., Shilling, J. E., Chen, Q., and Martin, S. T.: Increased cloud activation potential of secondary organic aerosol for atmospheric mass loadings, Atmos. Chem. Phys., 9, 2959-2971, doi:10.5194/acp-9-2959-2009, 2009.

King, S. M., Rosenoern, T., Shilling, J. E., Chen, Q., Wang, Z., Biskos, G., McKinney, K. A., Pöschl, U., and Martin, S. T.: Cloud droplet activation of mixed organic-sulfate particles produced by the photooxidation of isoprene, Atmos. Chem. Phys., 10, 3953-3964, doi:10.5194/acp-10-3953-2010, 2010.

Kostenidou, E., Pathak, R. K., and Pandis, S. N.: An algorithm for the calculation of secondary organic aerosol density combining AMS and SMPS data, Aerosol Sci. Technol., 41, 1002-1010, 2007.

Lewis, A. C., Carslaw, N., Marriott, P. J., Kinghorn, R. M., Morrison, P., Lee, A. L., Bartle, K. D., and Pilling, M. J.: A larger pool of ozone-forming carbon compounds in urban atmospheres, 
Nature, 405, 778-781, 2000.

Liu, X. and Wang, J.: How important is organic aerosol hygroscopicity to aerosol indirect forcing?, Environ. Res. Lett., 5, 1-10, doi:10.1088/1748-9326/5/4/044010, 2010.

McFiggans, G., Topping, D. O., and Barley, M. H.: The sensitivity of secondary organic aerosol component partitioning to the predictions of component properties - Part 1: A systematic evaluation of some available estimation techniques, Atmos. Chem. Phys., 10, 10255-10272, doi:10.5194/acp-10-10255-2010, 2010.

Myrdal, P. B. and Yalkowsky, S. H.: Estimating pure component vapor pressures of complex organic molecules, Ind. Eng. Chem.Res., 36, 2494-2499, 1997.

Nannoolal, Y., Rarey, J., Ramjugernath, D., and Cordes, W.: Estimation of pure component properties Part 1. Estimation of the normal boiling point of non-electrolyte organic compounds via group contributions and group interactions, Fluid Phase Equilibr., 226, 45-63, 2004.

Nannoolal, Y., Rarey, J., and Ramjugernath, D.: Estimation of pure component properties. Part 3. Estimation of the vapor pressure of non-electrolyte organic compounds via group contributions and group interactions, Fluid Phase Equilibr., 269, 117-133, 2008.

Ng, N. L., Kroll, J. H., Chan, A. W. H., Chhabra, P. S., Flagan, R. C., and Seinfeld, J. H.: Secondary organic aerosol formation from m-xylene, toluene, and benzene, Atmos. Chem. Phys., 7, 3909-3922, doi:10.5194/acp-7-3909-2007, 2007.

Petters, M. D. and Kreidenweis, S. M.: A single parameter representation of hygroscopic growth and cloud condensation nucleus activity, Atmos. Chem. Phys., 7, 1961-1971, doi:10.5194/acp-71961-2007, 2007.

Prenni, A. J., Petters, M. D., Kreidenweis, S. M., DeMott, P. J., and Ziemann, P. J.: Cloud droplet activation of secondary organic aerosol, J. Geophys. Res., 112, D10223, doi:10.1029/2006JD007963, 2007.

Raatikainen, T. and Laaksonen, A.: A simplified treatment of surfactant effects on cloud drop activation, Geosci. Model Dev., 4, 107-116, doi:10.5194/gmd-4-107-2011, 2011.

Seinfeld, J. H. and Pandis, S. N.: Atmospheric Chemistry and Physics - From Air Pollution to Climate Change (2nd Edition), John Wiley \& Sons, 2006.
Solomon, S., Qin, D., Manning, M., Chen, Z., Marquis, M., Averyt, K. B., Tignor, M., and Miller, H. L.: Contribution of Working Group I to the Fourth Assessment Report of the Intergovernmental Panel on Climate Change, 2007.

Sorjamaa, R. and Laaksonen, A.: The effect of $\mathrm{H} 2 \mathrm{O}$ adsorption on cloud drop activation of insoluble particles: a theoretical framework, Atmos. Chem. Phys., 7, 6175-6180, doi:10.5194/acp-76175-2007, 2007.

Stein, S. E. and Brown, R. L.: Estimation of Normal Boiling Points from Group Contributions, J. Chem. Inf. Comp. Sci., 34, 581587, 1994.

Swietlicki, E., Hansson, H.-C., Hämeri, K., Svenningsson, B. Massling, A., McFiggans, G., McMurry, P., Petäjä, T., Tunved, P., Gysel, M., Topping, D., Weingartner, E., Baltensperger, U., Rissler, J., Wiedensohler, A., and Kulmala, M.: Hygroscopic properties of sub-micrometer atmospheric aerosol particels measured with H-TDMA instruments in various environments - a review, Tellus B, 60, 432-469, 2008.

Tang, I. N. and Munkelwitz, H. R.: Composition and temperature dependence of the deliquescence properties of hygroscopic aerosols, Atmos. Environ., 27A(4), 467-473, 1994.

Topping, D.: An analytical solution to calculate bulk mole fractions for any number of components in aerosol droplets after considering partitioning to a surface layer, Geosci. Model Dev., 3, 635642, doi:10.5194/gmd-3-635-2010, 2010.

Topping, D. O., McFiggans, G. B., Kiss, G., Varga, Z., Facchini, M. C., Decesari, S., and Mircea, M.: Surface tensions of multicomponent mixed inorganic/organic aqueous systems of atmospheric significance: measurements, model predictions and importance for cloud activation predictions, Atmos. Chem. Phys., 7, 2371-2398, doi:10.5194/acp-7-2371-2007, 2007.

Wang, J., Lee, Y.-N., Daum, P. H., Jayne, J., and Alexander, M. L.: Effects of aerosol organics on cloud condensation nucleus $(\mathrm{CCN})$ concentration and first indirect aerosol effect, Atmos. Chem. Phys., 8, 6325-6339, doi:10.5194/acp-8-6325-2008, 2008.

Wex, H., Petters, M. D., Carrico, C. M., Hallbauer, E., Massling, A., McMeeking, G. R., Poulain, L., Wu, Z., Kreidenweis, S. M., and Stratmann, F.: Towards closing the gap between hygroscopic growth and activation for secondary organic aerosol: Part $1-$ Evidence from measurements, Atmos. Chem. Phys., 9, 39873997, doi:10.5194/acp-9-3987-2009, 2009. 